\title{
Pattern of use of radiotherapy for lung cancer: a descriptive study
}

\author{
Isabel Tovar ${ }^{1 *}$, Jose Expósito ${ }^{1}$, Javier Jaén ${ }^{2}$, Enrique Alonso ${ }^{3}$, Miguel Martínez $^{1}$, Rosa Guerrero ${ }^{1}$, \\ Juan P Arrebola ${ }^{1,4}$ and Rosario Del Moral ${ }^{1}$
}

\begin{abstract}
Background: Lung cancer remains one of the most prevalent forms of cancer. Radiotherapy, with or without other therapeutic modalities, is an effective treatment. Our objective was to report on the use of radiotherapy for lung cancer, its variability in our region, and to compare our results with the previous study done in 2004 (VARA-I) in our region and with other published data.

Methods: We reviewed the clinical records and radiotherapy treatment sheets of all patients undergoing radiotherapy for lung cancer during 2007 in the 12 public hospitals in Andalusia, an autonomous region of Spain. Data were gathered on hospital, patient type and histological type, radiotherapy treatment characteristics, and tumor stage.

Results: 610 patients underwent initial radiotherapy. 37\% of cases had stage III squamous cell lung cancer and were treated with radical therapy. $81 \%$ of patients with non-small and small cell lung cancer were treated with concomitant chemo-radiotherapy and the administered total dose was $\geq 60$ Gy and $\geq 45$ Gy respectively. The most common regimen for patients treated with palliative intent (44.6\%) was $30 \mathrm{~Gy}$. The total irradiation rate was $19.6 \%$ with significant differences among provinces (range, 8.5-25.6\%; $\mathrm{p}<0.001$ ). These differences were significantly correlated with the geographical distribution of radiation oncologists $(r=0.78 ; p=0.02)$. Our results were similar to other published data and previous study VARA-I.

Conclusions: Our results shows no differences according to the other published data and data gathered in the study VARA-I. There is still wide variability in the application of radiotherapy for lung cancer in our setting that significantly correlates with the geographical distribution of radiation oncologists.
\end{abstract}

Keywords: Non-small cell lung cancer, Radiotherapy, Clinical practice patterns, Small cell lung cancer

\section{Background}

Lung cancer (LC) is a worldwide health problem [1]. In Spain, approximately 20000 new cases are reported each year and 18000 individuals die from this disease. LC is the first cause of cancer mortality in men and the third in women (after breast and colorectal carcinomas) [1]. The incidence in women is 6-fold lower than in men but is increasing, as in other Western countries $[2,3]$.

Non-small cell lung cancer (NSCLC) accounts for $80 \%$ of all LCs, and the tumor load (stage) at the time of diagnosis is a critical factor for its clinical management [4].

\footnotetext{
*Correspondence: aris.tovar@gmail.com

${ }^{1}$ Radiation Oncology Department, Virgen de las Nieves Universitary Hospital, Granada, Spain

Full list of author information is available at the end of the article
}

According to clinical evidence accumulated over the past decades, optimal outcomes are obtained if tumors are treated in early stages, when surgery is more feasible. When this is not possible, there is a strong consensus that a multidisciplinary approach is warranted [5]. Thus, clinical guidelines recommend the combination of chemotherapy (CT) and radiotherapy (RT) in different schedules for patients with tumor stage II, IIIA, and IIIB. CT is recommended for the majority of patients with stage IV LC, depending on their performance status, and RT is used for palliative treatment [6-8]. CT-RT is the standard treatment for small cell lung cancer (SCLC) patients with limited disease. In general, preventive whole brain RT is recommended after CT-RT. CT is the treatment of choice

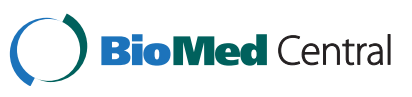


for SCLC patients with extensive disease, and RT is used in palliative treatments $[6,7]$.

RT has proven to be an effective treatment in LC, with or without other therapeutic modalities $[1,9]$. However, several studies $[10,11]$ have shown wide variations in its management among hospitals, including differences in utilization rate and schedules in both NSCLC and SCLC patients. Variability in medical practice (VMP) can imply worse outcomes, greater morbidity, higher social costs and lower cost-effectiveness. For these reasons, there has been an increase in VMP studies, which usually attempt to explain any geographic variations in terms of the accessibility of human and technical resources. In many cases, however, differences in the type of professional practice may play a role in this variability $[12,13]$.

We previously conducted a study that focused on the RT utilization rate and the patterns of RT application in patients with breast, lung, gynaecology and head and neck cancer (Variability and Appropriateness of Radiotherapy in Andalusia [VARA] project I) in Andalusian public hospitals in 2004 [14]. This study attributed the inter-hospital variability in RT management schedules, doses, fractionations to the low treatment unit: inhabitant ratio (three per million inhabitants) $(\mathrm{r}=0.823 / \mathrm{p}=$ $0.001)$ and number of radiation oncologists $(r=0.888 / p$ $<0.001$ ). In addition, we found the greatest variability in RT for LC (for example, in NSCLC the administered dose $\geq 60$ Gy ranged between $0 \%$ and $28,1 \%$ according to the hospital). A program launched in 2004 to improve regional RT resources led to ratio of 4.2 treatment units per million inhabitants by 2006 . The objective of the present study was to describe the variations in LC management among regional cancer centers in Andalusia during 2007.

\section{Methods}

A retrospective longitudinal study was conducted during 2007 in all of the 12 public hospitals that offered RT treatments in Andalusia, an autonomous region of Southern Spain with 8.4 million inhabitants. These centers are distributed among the eight provinces of the region, ensuring coverage of the whole population. Only $10 \%$ of the total care is delivered in private healthcare facilities in the region.

We reviewed the clinical records and treatment of all patients who received external beam RT as primary treatment (after the diagnosis, excluding patients who receive RT for relapse or progression of the disease after the first treatment) for LC of any histological type or stage with radical or palliative intent based on the treatment intent recorded in the charts. Data were obtained from the hospital discharge information system (Minimum Basic Data Set), hospital cancer registries, and clinical management computer systems linked to the RT equipment (Varis ${ }^{\circ}$, Lantis ${ }^{\circ}$ and
Impac $^{\ominus}$ networks). Demographic information was obtained from the Spanish National Statistics Institute (http://www. ine.es) [15], and estimates of the incidence of cancer in the Andalusian population and its distribution by histological type and stage were extrapolated from data from the Population Cancer Registry of Granada [16] and Carlos III Institute of Health, Madrid [2]. Trained researchers supervised by the staff at each center obtained patient data from the clinical records and individual treatment records.

Study variables included characteristics of the hospital (province, megavoltage units, and professionals), patient (age, gender, histological type, performance status estimated with Eastern Cooperative Oncology Group (ECOG) scale or Karnofsky scale, weight loss, and co-morbidity), and treatment (medical indication: therapeutic intent, total doses, fractions, nodal irradiation, delay, days of treatment, planning with $2 \mathrm{D}$ or $3 \mathrm{D}$, electron linear accelerator or cobalt 60 treatment, and adverse effects).

Statistical procedures. Descriptive outcomes are shown as means, medians, standard deviations and confidence intervals. The bivariate analysis was performed using chi-square test and Student t-test. SPSS version 12.0 (SPSS, Chicago IL) was used for statistical analyses. The significance level was set at $\mathrm{p}<0.05$ and all tests were two-tailed.

Ethical considerations. This was a retrospective study with no diagnostic or therapeutic implications. The research was approved by the Andalusian Ethics Committee for Clinical Trials.

\section{Results}

\section{Patients}

Out of the 3051 diagnosed cases of LC during the study period in the population of Andalusia, we collected data on the 610 patients who received RT as primary treatment for the disease. The majority of patients were male (91\%), and the median age was 65 years $(65 \pm 10.4$ years); $37 \%$ of cases had squamous cell carcinoma, $17 \%$ adenocarcinomas, $15 \%$ large-cell undifferentiated carcinoma, $12 \%$ NSCLCs of other histologies, and 19\% SCLC.

Missing data were related to performance status (47\%), co-morbidity (26\%), weight loss (44\%), and toxicity (77\%). However, $44 \%$ of cases (268 patients) had a good performance (ECOG $0-1$ ) and $60 \%$ showed a weight loss $\leq 10 \%$.

The patients were staged according to TNM $6^{\text {th }}$ edition [17].

\section{Hospital and treatments}

The distribution of the results by province is shown in Table 1.

Out of the 610 patients in the study, 58\% were treated with radical therapy ( $8 \%$ with adjuvant RT post-surgery) and $42 \%$ were treated with palliative therapy. The diagnosis 
Table 1 Distribution by province and proportion of patients treated with radical (R) or palliative intent (P)

\begin{tabular}{|c|c|c|c|c|}
\hline Provinces & LC patients treated with $\mathrm{RT}$ & LC patients treated with RT (\%) & Patients diagnosed with LC & RT rate $(\%)^{*}$ \\
\hline 1 & 21 (R 7 P 14) & 3 (R 33 P 67) & 244 & 9 \\
\hline 2 & 54 (R 40 P 14) & 9 (R 74 P 26) & 458 & 12 \\
\hline 3 & 70 (R 32 P 38) & 11 (R 46 P 54) & 305 & 23 \\
\hline 4 & 87 (R 77 P 10) & 14 (R 89 P 11) & 336 & 26 \\
\hline 5 & 48 (R 28 P 20) & 8 (R 58 P 42) & 183 & 26 \\
\hline 6 & 48 (R 39 P 9) & 8 (R 81 P 19) & 244 & 20 \\
\hline 7 & 132 (R 76 P 56) & 22 (R 58 P 42) & 580 & 23 \\
\hline 8 & 150 (R 57 P 93) & 25 (R 38 P 62) & 701 & 21 \\
\hline Total & 610 (R 356 P 254) & $100 \%$ (R 58 P 42) & 3051 & 20 \\
\hline
\end{tabular}

*Statistically significant difference $\mathrm{p}<0.001$.

was NSLCL in 494 patients (81\%) and SCLC in 116 (19\%); $62 \%$ of the NSCLC patients had stage III disease, and $71 \%$ of the SCLC patients had limited disease (Table 2).

Computed tomography-based RT treatment planning was performed in $95.1 \%$ of cases, and linear accelerator treatment was applied in $70.7 \%$.

Associated CT was received by over half of the patients (sequential CT by $30.3 \%$, concomitant CT by $34.34 \%$, and both by $4.4 \%$ ). As shown in Table 3 , the most common $\mathrm{CT}$ regimen was a platin (cisplatin or carboplatin) combined with taxol $24.5 \%$, gemcitabine $14.2 \%$ or vinorelbine $13.2 \%$ or etoposide $28.3 \%$. Etoposide was used in SCLC.

\section{Radical radiotherapy in NSCLC}

Radical RT was applied to 274 NSCLC patients, whose characteristics (gender and age) were similar to those of the whole series. Most of them had squamous cell carcinoma with an advanced stages; $58 \%$ had an ECOG of $0-1$, and $42 \%$ did not show a weight loss $>10 \%$. A regimen of $\geq 60$ Gy with standard fractionation (1.8-2 Gy per fraction) was administered to $74 \%$ of the patients. The irradiation field contained the mediastinal area in $81 \%$ of cases. The interval between the ordering and commencement of the treatment was $<30$ days in $49.7 \%$ of patients. CT associated with RT was the most common approach (sequential in $32.6 \%$, concomitant in $41.7 \%$, and both in $5.1 \%$ of cases). The CT schedule was a platin (cisplatin or carboplatin) with taxol, vinorelbine, or gemcitabine.

\section{Radical radiotherapy in SCLC}

Radical RT was applied to 82 SCLC patients, whose characteristics (gender and age) were similar to those of the whole series. The majority of patients had limited stage with good performance status (ECOG 0-1 in 87\%), although weight loss was more frequent (57\%). 97\% of patients received doses $\geq 45$ Gy with standard fractionation RT; (only 9 patients underwent a hypofractionated schedule). RT treatment was delayed for $>30$ days in $67 \%$, probably due to the CT treatment. All patients were treated with CT (sequential in $26 \%$, and concomitant in 63\%). All except four patients received cisplatin (or carboplatin) plus etoposide.

Table 4 summarizes the characteristics of radical RT for NSCLC and SCLC.

\section{Palliative radiotherapy (NSCLC and SCLC)}

The majority of patients undergoing palliative RT were diagnosed with NSCLC (86.6\%), mainly squamous cell carcinoma (39\%); $44.8 \%$ were with advanced stages, $30 \%$ had an ECOG of 2-4, and 44\% showed weight loss.

The most frequent RT schedule (in $44.6 \%$ of these patients) was 30 Gy (10 fractions $\times 3$ Gy per fraction) (Table 5). CT was not received by almost $40 \%$ of these patients. The interval from the consultancy to palliative RT was $<15$ days in $40 \%$ of the patients.

\section{Comparative study}

Statistically significant differences among provinces were found in the histology and stage of cancers and in RT

Table 2 Distribution by stage and histology

\begin{tabular}{|c|c|c|c|c|c|c|c|}
\hline \multicolumn{4}{|c|}{ NSCLC N = 494 (81\%) } & \multicolumn{4}{|c|}{ SCLC N = 116 (19\%) } \\
\hline Stage & $\mathrm{N}(\%)$ radical & $\mathrm{N}(\%)$ palliative & Total (\%) & Stage & $\mathrm{N}(\%)$ radical & $\mathrm{N}(\%)$ palliative & Total (\%) \\
\hline 1 & $17(6.2)$ & $4(2)$ & $21(4.2)$ & & & & \\
\hline II & $33(12.1)$ & $8(3.7)$ & $41(8.3)$ & Limited & $82(71)$ & - & $82(71)$ \\
\hline III & $179(65.3)$ & $125(57)$ & $304(61.5)$ & & & & \\
\hline IV & $45(16.4)$ & $83(37.3)$ & $128(26)$ & Extended & - & $34(29)$ & $34(29)$ \\
\hline$n=610$ & $274(55.4)$ & $220(44.6)$ & $494(100)$ & & $82(71)$ & $34(29)$ & $116(100)$ \\
\hline
\end{tabular}


Table 3 Associated chemotherapy and regimens

\begin{tabular}{|c|c|c|c|c|c|}
\hline \multicolumn{3}{|c|}{ Associated chemotherapy } & \multicolumn{3}{|l|}{ Regimen } \\
\hline & \multicolumn{2}{|c|}{ Patients (\%) } & & \multicolumn{2}{|c|}{ Patients (\%) } \\
\hline & NSCLC & SCLC & & NSCLC & SCLC \\
\hline No & $163(33)$ & $16(14)$ & CDDP + Taxol & $15(3)$ & - \\
\hline Sequential & $153(31)$ & $35(30)$ & Carbo + Taxol & $153(31)$ & - \\
\hline Concomitant & $153(31)$ & $59(51)$ & $\mathrm{CDDP}+\mathrm{GMZ}$ & $84(17)$ & $2(2)$ \\
\hline Both & $25(5)$ & $6(5)$ & $\mathrm{CDDP}+\mathrm{VNB}$ & $84(17)$ & $2(2)$ \\
\hline \multirow[t]{4}{*}{ Total } & $494(100)$ & $116(100)$ & CDDP + VP-16 & $15(3)$ & $53(46)$ \\
\hline & & & Carbo + VP-16 & $15(3)$ & $52(45)$ \\
\hline & & & Other & $128(26)$ & $7(5)$ \\
\hline & & & Total & $494(100)$ & $116(100)$ \\
\hline
\end{tabular}

$\mathrm{CDDP}=$ cisplatin; Carbo = carboplatin; VNB = vinorelbine; GMZ = gemcitabine; $\mathrm{VP}-16$ = etoposide.

intent, fractionation, and associated CT $(\mathrm{p}<0.05)$ (Tables 1 and 6).

Significant interprovincial differences in irradiation rate were found $(\mathrm{p}<0.001)$ and were significantly correlated with the inter-provincial distribution of radiation oncologists $(r=0.66 ; p=0.004)$ (Table 1, Figure 1).

We could not correlate the variability in the histology and stage of cancer with radiotherapy intent, fractionation, associated CT or radiation rate.

When we compared our data with those gathered from VARA-I study, we could observe an increase in total dose administered in both NSCLC and SCLC $(\mathrm{p}<0.01)$, stage (only statistically significant in NSCLC, $\mathrm{p}>0.01$ ) with slight increase in advanced stages in our study, and patients treated with palliative intent (only statistically significant in NSCLC, $\mathrm{p}=0.028$ ). After the program to improve regional RT resources based on VARA-I results, the radiation rate increased by $4 \%$ from $16 \%$ in 2004 to $20 \%$ in 2007 ( $<<0.001)$ (Table 7).

Table 4 Characteristics of radical radiotherapy in NSCLC and SCLC patients

Radical radiotherapy in NSCLC

\begin{tabular}{|c|c|c|c|c|c|c|c|c|}
\hline \multicolumn{2}{|c|}{ Histology (\%) } & \multicolumn{2}{|c|}{ Stage (\%) } & \multicolumn{2}{|c|}{ RT dose (\%) } & RT delay (\%) & \multicolumn{2}{|c|}{$\begin{array}{c}\text { Associated } \\
\text { CT (\%) }\end{array}$} \\
\hline SCC & 48.1 & I & 6.2 & $<60$ Gy & 26 & $<30$ days 49.7 & No & 20.6 \\
\hline$A D C$ & 21.7 & II & 12.1 & $\geq 60 \mathrm{~Gy}$ & 74 & $\geq \mathbf{3 0}$ days 50.3 & Seq & 32.6 \\
\hline LCUC & 17.5 & III & 65.3 & & & & Conc & 41.7 \\
\hline Others & 12.7 & IV & 16.4 & & & & Both & 5.1 \\
\hline \multicolumn{9}{|c|}{ Radical radiotherapy in SCLC } \\
\hline \multicolumn{2}{|c|}{ RT dose (\%) } & \multicolumn{4}{|c|}{ RT delay (\%) } & \multicolumn{3}{|c|}{ Associated CT (\%) } \\
\hline$<45 \mathrm{~Gy}$ & & 3 & $<30 c$ & lays & 33 & No & 0 & \\
\hline \multirow[t]{3}{*}{$\geq 45 \mathrm{~Gy}$} & & 97 & $\geq 30 \mathrm{c}$ & lays & 67 & Sequential & 26 & \\
\hline & & & & & & Concomitant & 63 & \\
\hline & & & & & & Both & 11 & \\
\hline
\end{tabular}

SCC: squamous cell carcinoma, ADC: adenocarcinoma, LCUC: Large-cell undifferentiated carcinoma. Seq: sequential, Conc: concomitant.
Overall, our data were in agreement with other published data (Table 8) [18-25].

\section{Discussion}

The role of RT as an effective treatment in LC is clearly established in clinical practice guidelines [6-8]. Most of the patients in this Spanish survey were male, as reported previously in this and other countries; there has been a progressive increase in LC incidence among women in Spain, but it remains considerably lower than in the USA $[20,26,27]$.

The mean age at LC onset diagnosis is 65 years in our region, within the range of 63-67 years reported in other Spanish series, and the majority of LC patients are diagnosed with NSCLC in an advanced stage [20,26,27]. The most frequent histological type is squamous cell carcinoma, although the incidence rates for adenocarcinoma show a rising trend and may possibly become higher than those for squamous cell carcinoma in the future [20,26,27].

Thus, our results were not different from other published studies.

Majority (74\%) of the NSCLC patients undergoing radical RT received $\geq 60$ Gy with standard fractionation, and the irradiation field contained the mediastinal area in

Table 5 RT schedules for LC treated with palliative intent

\begin{tabular}{ll}
\hline Radiotherapy schedule & Total (\%) \\
\hline Conventional fractionation (1.8-2 Gy) & $16.5 \%$ \\
$\mathbf{3}$ fractions x $\mathbf{4 0 0}$ cGy & $0.4 \%$ \\
$\mathbf{1 5}$ fractions x $\mathbf{3 0 0}$ cGy & $10.3 \%$ \\
$\mathbf{1 0}$ fractions x $\mathbf{3 0 0}$ cGy & $44.6 \%$ \\
$\mathbf{5}$ fractions x $\mathbf{4 0 0}$ cGy & $12.9 \%$ \\
$\mathbf{2}$ fractions x 850 cGy & $9.9 \%$ \\
$\mathbf{1}$ fraction x 800 cGy & $1.8 \%$ \\
Hyperfractionation & $0.4 \%$ \\
Other & $3.2 \%$ \\
\hline
\end{tabular}


Table 6 Statistically significant differences among provinces

\begin{tabular}{|c|c|c|c|c|c|c|c|}
\hline \multirow[t]{2}{*}{ Province } & \multicolumn{5}{|c|}{ Histology (\%) } & \multicolumn{2}{|c|}{ Stage (\%) } \\
\hline & SCC & ADC & LCUC & Others NSCLC & SCLC & Early (I-II) & Advanced (III-IV) \\
\hline 1 & 33.3 & 11.1 & 0 & 33.3 & 22.2 & 24.9 & 75.1 \\
\hline 2 & 28.3 & 28.3 & 19.6 & 13 & 10.9 & 25 & 75 \\
\hline 3 & 38.3 & 18.3 & 20 & 3.3 & 20 & 2 & 97.9 \\
\hline 4 & 31.1 & 13.5 & 29.7 & 2.7 & 23 & 13 & 87 \\
\hline 5 & 29.3 & 4.9 & 22 & 31.7 & 12.2 & 12.9 & 87.1 \\
\hline 6 & 57.1 & 21.4 & 2.4 & 2.4 & 16.7 & 11.2 & 88.9 \\
\hline 7 & 33.3 & 19.8 & 4.2 & 25 & 17.7 & 8.5 & 91.4 \\
\hline 8 & 46.6 & 13.6 & 10.2 & 2.3 & 27.3 & 10.7 & 89.4 \\
\hline \multirow[t]{2}{*}{ Province } & \multicolumn{3}{|c|}{ Fractionation (\%) } & \multicolumn{4}{|c|}{ Associated CT (\%) } \\
\hline & \multicolumn{2}{|c|}{ Conventional (1.8-2 Gy) } & Other & No & \multicolumn{3}{|c|}{ Yes } \\
\hline 1 & \multicolumn{2}{|c|}{50} & 50.1 & 47.1 & \multicolumn{3}{|c|}{52.9} \\
\hline 2 & \multicolumn{2}{|c|}{63.9} & 36.2 & 30.4 & \multicolumn{3}{|c|}{69.6} \\
\hline 3 & \multicolumn{2}{|c|}{45.9} & 54 & 15.5 & \multicolumn{3}{|c|}{84.4} \\
\hline 4 & \multicolumn{2}{|c|}{90.7} & 9.4 & 13.9 & \multicolumn{3}{|c|}{86.1} \\
\hline 5 & \multicolumn{2}{|c|}{54.8} & 45.3 & 56.1 & \multicolumn{3}{|c|}{43.9} \\
\hline 6 & \multicolumn{2}{|c|}{92.9} & 7.2 & 10.8 & \multicolumn{3}{|c|}{89.2} \\
\hline 7 & \multicolumn{2}{|c|}{46.9} & 52.9 & 47.9 & \multicolumn{3}{|c|}{52.2} \\
\hline 8 & \multicolumn{2}{|c|}{53.8} & 46.2 & 31.9 & \multicolumn{3}{|c|}{68.2} \\
\hline
\end{tabular}

SCC: squamous cell carcinoma, ADC: adenocarcinoma, LCUC: Large-cell undifferentiated carcinoma. NSCLC: non small cell lung cancer. SCLC: small cell lung cancer.

Statistically significant differences $(p<0.001$, with the exception of stage with $p=0,036$ ).

SCC: squamous cell carcinoma, ADC: adenocarcinoma, LCUC: Large-cell undifferentiated carcinoma. NSCLC: non small cell lung cancer. SCLC: small cell lung cancer.

$81 \%$ of them. This is the standard dose recommended in the literature for this entity [6-8]. Why the remainder $26 \%$ of patients were treated with a total dose lower than 60 Gy is unknown. Concomitant RT-CT was applied in $41.7 \%$ of the patients with inoperable NSCLC, which can be considered a low percentage given the worldwide acceptance of concomitant RT-CT as standard treatment option in these cases [6-8,28].

Almost all (97\%) of the patients with SCLC who were treated with radical intent received doses $\geq 45 \mathrm{~Gy}$, and

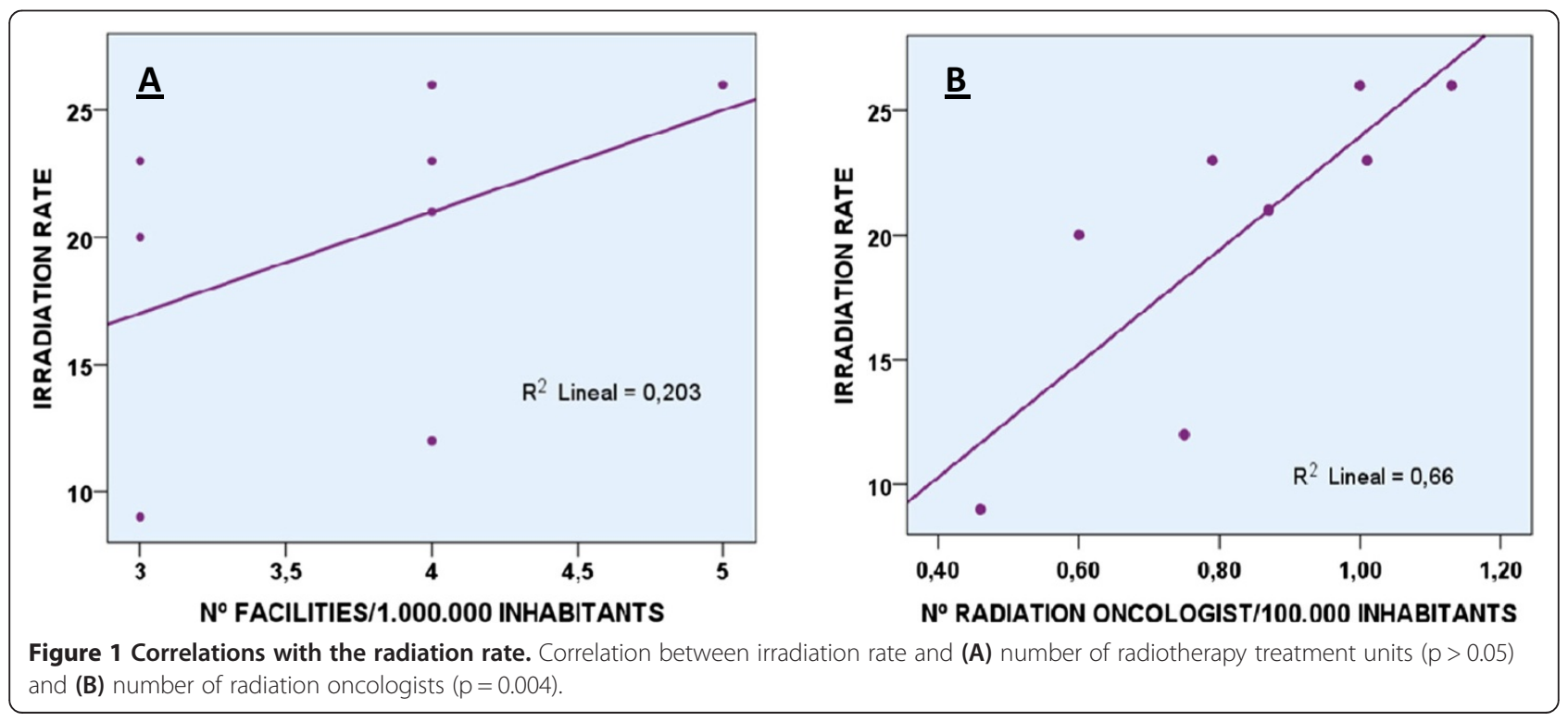


Table 7 Comparison with data from VARA-I

\begin{tabular}{|c|c|c|c|c|c|c|c|c|c|c|c|c|c|c|}
\hline \multicolumn{4}{|c|}{ Dose (\%) } & \multicolumn{3}{|c|}{ Associated CT (\%) } & \multicolumn{4}{|c|}{ Stage (\%) } & \multicolumn{4}{|c|}{ Intent (\%) } \\
\hline & & VARA'04 & VARA'07 & & VARA'04 & VARA'07 & & & VARA'04 & VARA'07 & & & VARA'04 & VARA'07 \\
\hline \multirow[t]{2}{*}{ NSCLC R } & $<60 \mathrm{~Gy}$ & $147(77.4)$ & $136(27.5)$ & No & $106(25.9)$ & $189(31)$ & NSCLC & $\mathrm{I} / \mathrm{II} / \mathrm{III}$ & $332(90)$ & $415(84)$ & NSCLC & $\mathbf{R}$ & $212(63.1)$ & $274(55.4)$ \\
\hline & $\geq 60 \mathrm{~Gy}^{*}$ & $43(22.6)$ & $358(72.5)$ & Yes $^{* *}$ & $303(74.1)$ & $421(69)$ & & $\mathbf{I V}^{\#}$ & $37(10)$ & $79(16)$ & & $P^{\# \#}$ & $124(36.9)$ & $220(44.6)$ \\
\hline \multirow[t]{2}{*}{ SCLC R } & $<45$ Gy & $33(54.1)$ & $1(1.2)$ & & & & SCLC & LS & $54(79.1)$ & $82(71)$ & SCLC & $\mathbf{R}$ & $54(79.1)$ & $82(71)$ \\
\hline & $\geq 45 \mathrm{~Gy}^{*}$ & $28(45.9)$ & $115(98.8)$ & & & & & $\mathrm{ES}^{\S}$ & $14(20.9)$ & $34(29)$ & & $P^{\S}$ & $14(20.9)$ & 34 (29) \\
\hline \multicolumn{2}{|c|}{ Age (years) ${ }^{\S}$} & \multicolumn{5}{|c|}{ Gender (\%) } & \multicolumn{4}{|c|}{ ECOG (\%) } & \multicolumn{4}{|c|}{ Radiation rate $(\%)^{*}$} \\
\hline \multicolumn{2}{|c|}{ VARA'04 } & \multicolumn{2}{|l|}{ VARA'07 } & & VARA'04 & VARA'07 & & \multicolumn{2}{|c|}{ VARA'04 } & VARA'07 & \multicolumn{2}{|c|}{ VARA'04 } & \multicolumn{2}{|c|}{ VARA'07 } \\
\hline \multirow[t]{5}{*}{$64,6 \pm 10,7$} & & $66 \pm 10$ & & q & $33(8)$ & $55(9)$ & $0 \S \S$ & $94(39$. & & $141(43.9)$ & \multirow{5}{*}{\multicolumn{2}{|c|}{$416(16)$}} & \multirow{5}{*}{\multicolumn{2}{|c|}{$610(20)$}} \\
\hline & & & & $\delta^{\wedge}$ & $383(92)$ & 555 (91) & 1 & $85(36)$ & & $131(40.7)$ & & & & \\
\hline & & & & & & & 2 & $36(15$ & & $40(12.5)$ & & & & \\
\hline & & & & & & & 3 & $18(7.6)$ & & $7(2.2)$ & & & & \\
\hline & & & & & & & 4 & $3(1.3)$ & & $2(0.7)$ & & & & \\
\hline
\end{tabular}

NSCLC: non small cell lung cancer. SCLC: small cell lung cancer. LS: limited stage. ES: extended stage. R: radical. P: Palliative.

Differences: ${ }^{*} \mathrm{p}<0.01 ;{ }^{* *} \mathrm{p}=0.08 ;{ }^{\#} \mathrm{p}=0.011 ;{ }^{\# \#} \mathrm{p}=0.028 ;{ }^{\S} \mathrm{p}>0.1 ;{ }^{\S \S} \mathrm{p}=0.02 ;{ }^{\wedge} \mathrm{p}=0.54$.

$63 \%$ of them received concomitant RT-CT. Evidence has been published on the benefits of early RT administration in this situation [11]. Among various RT schedules used to treat LC with palliative intent, the most frequent was 300 cGy $\times 10$ fractions. Differences in the schedules used are probably related to the different localizations of the sites under treatment.

Using a benchmark approach, Barbera L. et al. [29] estimated that initial RT was warranted in $49.3 \%$ of LC patients, and similar conclusions were reached by other authors using different study methods [30,31]. The European ESTRO QUARTS project [32] recommended RT in up to $61 \%$ of LC patients. In the present survey, the irradiation rate was $20 \%, 4 \%$ higher than recorded in our region in 2004 (17\% relative increase) but still low according to the estimated radiation rate, resulting in an underuse of RT for lung cancer [33].

We observed major and statistically significant variations among the eight provinces in the histology and stage of the disease and in RT intent, fractionation, associated CT (all $\mathrm{p}<0.05)$, and irradiation rate $(\mathrm{p}<0.001)$.

The few studies that addressed VMP in the context of RT reported variations in medical practice and the underutilization of RT for LC $[10,11,14,34]$. The initial articles by J E Wennberg on VMP [12,13] systematized the possible causes of differences as follows:

1. Demand: clinical stage, histology, incidence, age, delay and distance from the hospital... couldn't explain this variability according to our results. Socio-economic differences were not analyzed in this study [35], however the Andalusian health system is a public system with universal free coverage. Patient support system is another important factor but, considering the public health system of Andalusia, we believe that the contribution of this factor would be minimal.

2. Service offer: accessibility. If epidemiological causes are ruled out, resource gaps or limitations may in

Table 8 Comparison with other published data

\begin{tabular}{|c|c|c|c|c|c|c|c|c|c|c|c|c|c|}
\hline \multirow[t]{2}{*}{ Study } & \multirow[t]{2}{*}{ Age } & \multicolumn{2}{|c|}{ Gender (\%) } & \multicolumn{4}{|c|}{ Histology (\%) } & \multicolumn{6}{|c|}{ Stage (\%) } \\
\hline & & $\overline{\sigma^{2}}$ & q & $\overline{\mathrm{SCC}}$ & ADC & LCUC & $\overline{\mathrm{SCLC}}$ & 1 & II & III & IV & LS & ES \\
\hline Salmerón 2012 [18] & 67 & 90 & 10 & 37 & 20 & 8 & 16 & - & - & - & - & - & $\overline{-}$ \\
\hline Escuín 2009 [19] & 70 & - & - & 38 & - & - & 20 & - & - & - & - & - & - \\
\hline Prim 2010 [20] & 67 & 93 & 7 & 39 & 19 & 10 & 20 & 10 & 9 & 34 & 47 & 31 & 69 \\
\hline Escuín 2006 [21] & 68 & 89 & 11 & \multicolumn{3}{|c|}{79 CPNCP } & 21 & 20 & 4 & 37 & 35 & 37 & 61 \\
\hline Hernández 2004 [22] & 68 & 85 & 15 & 38 & 17 & 12 & 30 & - & - & - & - & - & - \\
\hline Santos-M 2005 [23] & 67 & 89 & 11 & 33 & 30 & 4 & 13 & 21 & & 35 & 42 & 44 & 55 \\
\hline Estrada 2007 [24] & 67 & 90 & 10 & 24 & 17 & 29 & 19 & 24 & 4 & 27 & 41 & - & - \\
\hline Alonso-F 2005 [25] & 67 & 92 & 8 & 58 & 29 & 5 & 19 & 27 & 7 & 35 & 31 & 47 & 53 \\
\hline VARA-II & 66 & 91 & 8 & 37 & 17 & 15 & 19 & 4 & 8 & 61 & 26 & 71 & 29 \\
\hline
\end{tabular}

SCC: squamous cell carcinoma, ADC: adenocarcinoma, LCUC: Large-cell undifferentiated carcinoma. SCLC: small cell lung cancer. LS: limited stage. ES: extended stage. 
part explain a low irradiation rate. In the present study, a lower irradiation rate was significantly correlated with a smaller number of radiation oncologists. In 2007, a mean of 4.2 megavoltage units were available per million inhabitants, and the treatment started a median of 41 days after it was ordered, with significant differences among hospitals.

3. Style of practice: medical practice patterns may explain the low irradiation rates found in our region $[36,37]$. Most clinical trials have a control arm with standard treatment that does not include RT $[38,39]$.

In many cases, the variability detected in RT intent, fractionation, and associated CT may be attributable to differences in styles of professional practice. There is increasing evidence that unexplained variations in practice are widespread in oncology in general. However, the problem is not confined to oncology; it should be taken into account that RT programs maintain unusually good records, and the excellence of the information systems makes variations in practice highly visible [10].

Our results weren't different from other published data and some differences (such as stage) can be due to our study only collecting patients treated with initial radiotherapy.

Regarding VARA-I, radiation rate, administered total dose, advanced stage and radiotherapy with palliative intent have increased. Thus, we can say that, although we have more confidence to give more total dose, the radiation rate has increased due to radiotherapy administered with palliative intent.

One study limitation is its retrospective and hospital population-based design, which means that the total number of patients irradiated for LC may be underestimated, because the patients who were treated in private centers and patients who might have travelled out of Andalusia weren't collected. However, mobility interregions is an uncommon situation in our area, only $10 \%$ of the total care is delivered in private centers, and the data observed were consistent with the findings of the previous survey (VARA I) 3 years earlier and the descriptive analysis and the results obtained weren't different from other published data. Other important limitation is the time between the year of the study (2007) and its publication (2013). Nowadays the health system is probably different regarding 2007. This is a common fact among the population study. However between VARA-I and VARA-II (period of time of three years) the situation was not very different. New techniques of treatment, as stereotactic body radiotherapy, are being implemented now, and no many centers have this technology. Therefore, our study can reflect very accurate picture of the use of RT in our health area.

\section{Conclusions}

Although our results were in agreement with other published data and the irradiation rate has increased, this study shows some variability in care patterns for LC in our region. The irradiation rate significantly differs among the provinces and is correlated with the inter-provincial distribution of radiation oncologists. Significant interhospital differences were detected in the histology and stage of LC and in its management (RT intent, fractionation, and associated CT). According to the literature, variations in medical practice and underuse of RT are a worldwide problem that needs to be study and this research is an example of this. It is necessary to examine variations in practice and distinguish those that are appropriate from those that are not justified and must be eliminated.

\section{Abbreviations}

LC: Lung Cancer; NSCLC: Non-Small Cell Lung Cancer; CT: Chemotherapy; RT: Radiotherapy; SCLC: Small Cell Lung Cancer; VMP: Variability in Medical Practice; VARA: Variability and Appropriateness of Radiotherapy in Andalusia; ECOG: Eastern Cooperative Oncology Group.

\section{Competing interest}

The authors declare that they have no competing interests.

\section{Authors' contributions}

IT participated in the quality control of data and algorithms, data analysis and interpretation, statistical analysis, manuscript preparation, manuscript editing and manuscript review. JE carried out the study concepts, study design, quality control of data and algorithms, data analysis and interpretation and manuscript review. JJ participated in the study concepts, study design and data acquisition. EA carried out the study concepts, study design and data acquisition. MM participated in data acquisition and analysis, interpretation and manuscript review. RG participated in data acquisition and analysis, interpretation and manuscript review. JPA reviewed the manuscript and participated in the data analysis. DR participated in the data analysis and interpretation, statistical analysis, manuscript preparation, manuscript editing and manuscript review. All authors read and approved the final manuscript.

\section{Acknowledgements}

The authors gratefully acknowledge scientific and technical assistance provided by Richard Davies. Dr J.P. Arrebola is currently receiving a postdoctoral contract from the Consejería de Igualdad, Salud y Políticas Sociales, Junta de Andalucía (RH-0092-2013). The results would not have been achieved without the selfless collaboration of the staff involved in the data acquisition: Amalia Palacios (Reina Sofía University Hospital, Córdoba); Eloisa Bayo (Juan Ramón Jiménez Hospital, Huelva); José Antonio Sánchez Calzado (Virgen Macarena University Hospital, Sevilla); Ma José Ortiz (Virgen del Rocío University Hospital, Sevilla); Ismael Herruzo Cabrera (Carlos Haya University Hospital, Málaga); José Antonio Medina (Virgen de la Victoria University Hospital, Málaga); Francisco Peracaula 8Punta Europa Hospital, (ádiz).

\section{Funding}

This work was supported by the Public Health System of Andalusia (Grant number 0266/2007). The funding body did not have influence on the results.

\section{Author details}

${ }^{1}$ Radiation Oncology Department, Virgen de las Nieves Universitary Hospital, Granada, Spain. ${ }^{2}$ Institute of Oncology, Cartuja, Sevilla, Spain. ${ }^{3}$ Radiation Oncology Department, Puerta del Mar Universitary Hospital, Cádiz, Spain. ${ }^{4}$ CIBER en Epidemiología y Salud Pública (CIBERESP), Granada, Spain. 
Received: 6 July 2013 Accepted: 18 September 2014

Published: 23 September 2014

\section{References}

1. Halpering EC, Perez CA, Brady LW: Principles and Practice of radiation Oncology. Philadelphia: Lippincott Williams \& Wilkins; 2008.

2. Abente L: La Situación del Cáncer en España. Instituto de Salud Carlos III. Madrid: Ministerio de Sanidad y Consumo; 2005.

3. Sánchez de Cos J: LC in Spain. Current Epidemiology, Survival, and Treatment. Arch Bronconeumol 2009, 45(7):341-348.

4. Edge SB, Byrd DR, Compton CC, Fritz AG, Greene FL, Trotti A: Lung cancer. In AJCC Cancer Staging Manual. 7th edition. Edited by American Joint Committee on Cancer (AJCC). New York: Springer-Verlag; 2010:299-323.

5. Rubin P: Clinical Oncoly. A multidisciplinary approach for physicians and students. Philadelphia: WB Saunders Co.; 2001.

6. American College of Chest Physicians (ACCP): The LC Guideline. (2th edition). Chest 2007, 132(Suppl 3):1-328.

7. Cottish Intercollegiate Guideline Network: Management of patients with LC. A national clinical guideline. Scotland, United Kingdom: Scottish Intercollegiate Guideline Network. 2005. [http://www.sign.ac.uk/pdf/ sign80.pdf]

8. National Institute for Health and Clinical Excellence (NICE): The diagnoses and treatment of Lung Cancer (CG 121). [http://guidance.nice.org.uk/ cg121]

9. DeVita VT, Hellman S, Rosemberg SA: Cáncer. Médica Panamericana: Principios y Prácticas de Oncología. Madrid; 2000.

10. Mackillop WJ, Dixon P, Zhou Y, Ago CT, Ege G, Hodson DI, Kotalik JF, Lochrin C, Paszat L, Harris D: Variation in the management and outcome of non-small cell lung cancer in Ontario. Radiother Oncol 1994, 32(2):106-115.

11. Kepka L, Danilova V, Saghatelyan T, Bajcsay A, Utehina O, Stojanovic S, Yalman D, Demiral A, Bondaruk O, Kuddu M, Jeremic B, International Atomic Energy Agency (IAEA): Resources and management strategies for the use of radiotherapy in the treatment of lung cancer in Central and Eastern European countries: results of an International Atomic Energy Agency (IAEA) survey. Lung Cancer 2007, 56(2):235-245.

12. Wennberg JE, Gittelsohn AM: Variations in medical care among small areas. Sci Am 1982, 264:100-111.

13. Wennberg JE, Gittelsohn AM: A small area variations in health care delivery. A population-based health information system can guide planning and regulatory decision-making. Science 1973, 18:1.102-1.108.

14. Jaén J, Alonso E, Expósito J, de las Peñas MD, Cabrera P: Evidence-based estimation and radiotherapy utilization rate in Andalusia. Clin Translat Oncol 2007, 9:789-796

15. National Statistic Institute (NSI). [http//www.ine.es]

16. Granada Cancer Registry (GCR). [http://www.cancergranada.org/en/ granada_cancer_registry_about_us.cfm]

17. American Joint Committee on Cancer (AJCC): AJCC Cancer Staging Manual. New York, PA: Springer-Verlag; 2002

18. Salmerón D, Chirlaque MD, Isabel Izarzugaza M, Sánchez MJ, MarcosGragera R, Ardanaz E, Galceran J, Mateos A, Navarro C: Lung cancer prognosis in Spain: The role of histology, age and sex. Respir Med 2012, 106:1301-1308.

19. Escuín JS: Lung cancer in Spain. Current Epidemiology, Survival, and Treatment. Arch Bronconeumol 2009, 45(7):341-348.

20. Prim JM, Barcala FJ, Esquete JP, Reino AP, López AF, Cuadrado LV: Lung cancer in a health area of Spain: incidence, characteristics and survival. Eur J Cancer Care 2010, 19(2):227-233.

21. Sánchez de Cos Escuín J, Miravet Sorribes L, Abal Arca J, Núñez Ares A Hernández Hernández J, Castañar Jover AM, Muñoz Gutiérrez FJ, García Arangüena L, Alonso MA, Montero Martínez MC, Allende González J, Sánchez Hernández l: Estudio multicéntrico epidemiológico-clínico de cáncer de pulmón en España (estudio EpicliCP-2003). Arch Bronconeumol 2006, 42(9):446-452.

22. Hernández Hernández JR, del Pozo JA T, Moreno Canelo P, Rodríguez Puebla A, Paniagua Tejo S, Sánchez Marcos JC: Incidencia del cáncer de pulmón en la provincia de Ávila. Año 2002 y tendencias en una década. Arch Bronconeumol 2004, 40(7):304-310.

23. Santos-Martínez MJ, Curull V, Blanco ML, Macià F, Mojal S, Vila J, Broquetas JM: Lung cancer at a University Hospital: epidemiological and histological characteristics of a recent and a historical series. Arch Bronconeumol 2005, 41(6):301-312.

24. Estrada Trigueros G, Comeche L, López Encuentra A, Montoro Zulueta J, González Garrido F, Colina F: Carcinoma broncogénico 2000-2001: características y supervivencia global. Arch Bronconeumol 2007, 43(11):594-598.

25. Alonso-Fernández MA, García-Clemente M, Escudero-Bueno C: Características del carcinoma broncopulmonar en una región del norte de España. Arch Bronconeumol 2005, 41(9):478-483.

26. Alberg AJ, Ford JG, Samet JM: Epidemiology of lung cancer: ACCP evidence-based clinical practice guidelines (2nd edition). Chest 2007, 132(Suppl 3):29-55.

27. Janssen-Heijnen ML, Coebergh JW: The changing epidemiology o lung cancer in Europe. Lung Cancer 2003, 41(3):245-258.

28. Movsas B, Moughan J, Komaki R, Choy H, Byhardt R, Langer C, Goldberg M, Graham M, Ettinger D, Johnstone D, Abrams R, Munden R, Starkschall G, Owen J: Radiotherapy patterns of care study in lung carcinoma. J Clin Oncol 2003, 21:453-459.

29. Barbera L, Zhang-Salomon J, Huang J, Tyldesley S, Mackillop W: Defining the need for radiotherapy for lung cancer in the general population. A criterion-based, benchmarking approach. Medical Care 2003, 41(9):1074-1085

30. Tyldesley S, Delaney G, Foroudi F, Barbera L, Kerba M, Mackillop W: Estimating the need for radiotherapy for patients with prostate, breast, and lung cancers: verification of model estimates of need with radiotherapy utilization data from British Columbia. Int J Radiat Oncol Biol Phys 2011, 1; 79(5):1507-1515.

31. Delaney G, Jacob S, Featherstone C, Barton M: The role of radiotherapy in cancer treatment: estimating optimal utilization from a review of evidence-based clinical guidelines. Cancer 2005, 104:1129-1137.

32. Bentzen SM, Heeren G, Cottier B, Slotman B, Glimelius B, Lievens Y, van den Bogaert W: Towards evidence-based guidelines for radiotherapy infrastructure and staffing needs in Europe: the ESTRO QUARTS project. Radiother Oncol 2005, 75:355-365.

33. Tovar I, Expósito J, Jaén J, Alonso E: Underuse of radiotherapy in lung cancer has negative consequences for patients. J Thorac Oncol 2013 8(1):62-67.

34. Vinod SK, Simonella L, Goldsbury D, Delaney GP, Armstrong B, O'Connell DL: Underutilization of radiotherapy for lung cancer in New South Wales, Australia. Cancer 2010, 116(3):686-694.

35. Jack RH, Gulliford MC, Ferguson J, Møller H: Explaining inequalities in access to treatment in lung cancer. J Eval Clin Pract 2006, 12(5):573-582.

36. Tai $P, Y u$ E, Battista J, Van Dyk J: Radiation treatment of lung cancerpatterns of practice in Canada. Radiother Oncol 2004, 71(2):167-174.

37. Lee IH, Hayman JA, Landrum MB, Tepper J, Tao ML, Goodman KA, Keating NL: Treatment recommendations for locally advanced, non-small-cell lung cancer: the influence of physician and patient factors. Int J Radiat Oncol Biol Phys 2009, 74(5):1376-1384

38. Loannidis JPA, Pavlidis N: Levels of Absolute survival benefit for systematic therapies of advanced cancer: a call for standards. Eur J Canc 2003, 39:1194-1198.

39. Goffin J, Lacchetti C, Ellis PM, Ung YC, Evans WK: First-line chemotherapy in the treatment of advanced Non-small cell lung cancer. A systematic review. J Thorac Oncol 2010, 5:260-274.

doi:10.1186/1471-2407-14-697

Cite this article as: Tovar et al:: Pattern of use of radiotherapy for lung cancer: a descriptive study. BMC Cancer 2014 14:697. 